\title{
Recursos semióticos de enquadramento e a ressignificação espacial/interacional em tempos de pandemia da covid-19 no contexto educacional
}

\author{
Derli Machado de Oliveira* \\ Danielle Barbosa Lins de Almeida*
}

Resumo: Este trabalho tem como objetivo fazer uma análise qualitativo-interpretativa da ressignificação espacial/interacional em tempos de pandemia da Covid-19 no contexto educacional. Nossa análise buscou mostrar, com apoio da Semiótica Social (VAN LEEUWEN, 2005, 2008; KRESS e VAN LEEUWEN, 2006), o recurso semiótico de enquadramento na composição do espaço. A imagem fotográfica que utilizamos como objeto de análise foi publicada no jornal The Mirror (13/05/2020), em matéria sobre crianças francesas que regressaram à escola depois do período de quarentena. Constatamos que os recursos semióticos de enquadramento utilizados no espaço físico analisado foram de 'segregação' e de 'separação'. Palavras-chave: Semiótica social. Ressignificação espacial/interacional. Recursos semióticos.

\begin{abstract}
This work aims to make a qualitative-interpretative analysis of the spatial/ interactional resignification in times of the Covid-19 pandemic in the educational context. Our analysis sought to demonstrate, based on the Social Semiotic approach (VAN LEEUWEN, 2005, 2008; KRESS and VAN LEEUWEN, 2006) how the semiotic feature of framing works in the composition of space. Our data is a photograph published in the newspaper The Mirror (13th May 2020) showing French children returning to school after the quarantine period. We found that the semiotic framing resources used in the analyzed physical space were 'segregation' and 'separation'.
\end{abstract}

Keywords: Social semiotics. Spatial/interactional resignification. Semiotic resources.

Resumen: Este trabajo tiene como objetivo hacer un análisis cualitativo-interpretativo de la resignificación espacial / interaccional en tiempos de la pandemia de Covid-19 en el contexto educativo. Nuestro análisis buscó mostrar, con el apoyo de Social Semiotics (VAN LEEUWEN,

\footnotetext{
* Professor do Departamento de Letras (DLI) e do Mestrado Profissional em Letras da Universidade Federal de Sergipe (UFS). http://orcid.org/oooo-0002-5566-3317

${ }^{*}$ Professora Associada no Departamento de Línguas Estrangeiras Modernas (DLEM) e na Pós-Graduação em Linguística (PROLING) da Universidade Federal da Paraíba (UFPB). http://orcid.org/0000-0003-14726083
} 
2005, 2008; KRESS y VAN LEEUWEN, 2006), el recurso semiótico para enmarcar la composición del espacio. La imagen fotográfica que utilizamos como objeto de análisis fue publicada en The Mirror (13/05/2020), en un artículo sobre niños franceses que regresaron a la escuela después del período de cuarentena. Descubrimos que los recursos de estructura semiótica utilizados en el espacio físico analizado eran "segregación" y "separación".

Palabras clave: Semiótica social. Resignificación espacial/interaccional. Recursos semióticos.

\section{Introdução}

Devido à pandemia global da Covid-19, cujo início se deu nos primeiros meses de 2020, diversos países impuseram a quarentena (isolamento social), cuja medida principal consistiu na obrigatoriedade das pessoas ficarem em casa, além do fechamento do comércio, parques, praias, e a proibição de atividades não essenciais (culturais, recreativas e esportivas) que concentram muitas pessoas, incluindo também a suspensão de aulas nas escolas públicas e privadas (incluindo as creches), visando basicamente evitar aglomerações e conter a proliferação do vírus.

O isolamento social da população provocou profundas mudanças no campo das relações sociais. Novas formas (regras) de sociabilidade e novos processos de interação e comunicação surgiram na pandemia, visando basicamente romper com o alto grau de aproximação que havia anteriormente entre as pessoas, suprimindo o contato físico. Além da decretação da quarentena, especialistas da Organização Mundial de Saúde (OMS) recomendaram que interações físicas como beijos, abraços e apertos de mãos fossem evitadas.

Depois de alguns meses de fechamento, alguns países como a China e a França permitiram aos poucos a reabertura das escolas e creches. Todavia, para o que estão chamando de 'novo normal' ', algumas adaptações foram feitas desde a entrada das crianças na escola, como a obrigatoriedade do uso de máscaras, lavagem das mãos, número reduzido de alunos em sala de aula, as mesas/carteiras dos alunos foram reposicionadas, distanciamento corporal etc.

\footnotetext{
${ }^{1}$ Este conceito tem sido usado por autoridades, pesquisadores de várias áreas e a mídia para designar a construção de um novo padrão de normalidade do comportamento social diante da pandemia.
} 
Para a educação infantil os desafios são maiores. Como manter o distanciamento social com crianças na faixa etária de dois a quatro anos, por exemplo? Nessa idade a maioria das atividades pedagógicas desenvolvidas nas escolas e creches envolve brincadeiras com bastante contato físico e aproximação.

Diante disso, por meio de uma abordagem qualitativo-interpretativa, nossa análise buscou apoio na Semiótica Social com o objetivo de refletir sobre a ressignificação 'espaço/interacional' em tempos de pandemia no contexto educacional, por meio da análise dos recursos semióticos de enquadramento usados para distanciamento nos espaços. Utilizaremos como modelo de análise o inventário de tipos de enquadramento que van Leeuwen (2005) observou em um novo domínio, o enquadramento do espaço em escritórios e edifícios escolares. Ele constatou que os princípios semióticos multimodais realizam o mesmo trabalho semiótico tanto em representações verbais e visuais como em termos de realização física de pessoas e suas atividades: conectar ou desconectar, segregar ou separar, criar semelhança ou contraste.

Nosso objeto de análise é constituído por uma fotografia que foi publicada em 13/05/2020 no jornal online The Mirror (MIRROR, 2020), tabloide diário britânico fundado em 1903, em matéria sobre crianças francesas que regressaram à escola depois do período de quarentena por causa da pandemia, cuja imagem retrata o cenário de brincadeiras entre a professora e algumas crianças no pátio da escola, que agora precisam brincar à distância, em zonas delimitadas por marcas de giz no chão. A divulgação da foto causou comoção e indignação não só na França, mas também em vários países.

Este trabalho está dividido em quatro seções. Além desta introdução, na segunda apresentamos o aporte teórico-metodológico, o qual se baseia na abordagem da Semiótica Social (VAN LEEUWEN, 2005, 2008; KRESS e VAN LEEUWEN, 2006), que visa compreender a articulação dos diversos modos semióticos utilizados nas práticas sociais de comunicação em diferentes contextos. Por tratar-se de uma pesquisa de caráter transdisciplinar, buscamos aplicar também as contribuições de teóricos que tratam da infância e das brincadeiras e/ou brinquedos, como Borba (2007), Barbosa, Martins e Mello (2017), Arendt (1971), Kishimoto (1997), Brougère (2001) e Almeida (2006). 
Em seguida, na terceira seção, faremos a análise utilizando o esquema analítico proposto por van Leeuwen (2005) na pesquisa em que observou tipos de enquadramento em espaços de escritórios e edifícios escolares. Na quarta e última seção trazemos nossas considerações finais.

\section{Aporte teórico-metodológico}

Nesta seção, destacamos a natureza, objetivos, métodos e alguns conceitos-chave da Semiótica Social que serão importantes para o desenvolvimento deste estudo, como discurso, prática social, recurso semiótico, entre outros. Além disso, apresentamos o conceito de 'espaço em discurso', introduzido por van Leeuwen (2008), e um modelo de análise de tipos de enquadramento que ele observou em espaços de escritórios e edifícios escolares, o qual servirá para nossa análise (VAN LEEUWEN, 2005).

Por tratar-se de uma pesquisa de caráter transdisciplinar, nas revisões teóricas buscamos aplicar as contribuições de teorias que tratam da infância e das brincadeiras e/ou brinquedos.

Apresentada por Theo van Leeuwen (2005), um dos principais teóricos da Semiótica Social (doravante SS), como uma abordagem nova e distinta da semiótica estruturalista, a SS tem como principal objetivo a compreensão da articulação dos diversos modos semióticos utilizados nas práticas sociais de comunicação em diferentes contextos. A SS procura observar a relação intrínseca entre o signo e o social, afirmando que os signos não podem ser dissociados das formas concretas de relações sociais (VAN LEEUWEN, 2005).

Nesse sentido, a abordagem da SS procura observar não só os diversos tipos de significados presentes em um ato de comunicação, como também chama a atenção para o fato de que os signos e seus respectivos significados são produzidos de forma motivada em situações interacionais de membros de sociedades e culturas específicas.

Para ressaltar essa relação intrínseca entre o signo e o social, o autor reporta-se ao trabalho de Volochinov, um importante precursor da semiótica social, para quem “os 
signos não podem ser dissociados das formas concretas de relações sociais... e não pode existir, como tal, sem ele" (VAN LEEUWEN, 2005, p. 3 - 4, tradução nossa ${ }^{2}$ ).

Van Leeuwen (2005) destaca duas características essenciais dessa teoria: seu caráter interdisciplinar e investigativo. Sobre a interdisciplinaridade o autor afirma que a SS não é uma teoria 'pura', não é um campo independente, antes exige imersão em conceitos e métodos de algum outro campo. Em relação ao caráter investigativo, o autor afirma que a SS "Não oferece respostas prontas. Ela oferece ideias para formular perguntas e maneiras de procurar respostas" (VAN LEEUWEN, 2005, p. xiii, tradução nossa 3 ). Portanto, além de permitir que o investigador descreva os tipos de significados que um recurso semiótico pode ter, a SS ainda contribui para a descoberta e desenvolvimento de novos recursos semióticos e novos usos dos recursos semióticos existentes.

A seguir, abordamos alguns conceitos básicos para a SS. Iniciamos com a dimensão do discurso como recursos que representam práticas sociais:

[...] cognições sociais, formas socialmente específicas de conhecer práticas sociais, que podem ser e são usados como recursos para representar práticas sociais em texto (VAN LEEUWEN, 2008, p. 6, tradução nossa ${ }^{4}$ ).

Como os discursos podem ser realizados não apenas linguisticamente, mas também por meio de outros modos semióticos, a atenção às imagens deve ter um lugar de destaque em qualquer investigação sobre discurso, pois é preciso mostrar que nem sempre os sentidos que elas carregam estão explícitos (VAN LEEUWEN, 2008). Nesse sentido, a imagem fotográfica, a qual constituiu o objeto da nossa pesquisa, são discursos que representam as práticas sociais em textos.

Na abordagem teórica da SS “As práticas sociais são formas socialmente reguladas de fazer as coisas [...]" (VAN LEEUWEN, 2008, p. viii, tradução nossa5). Neste estudo

\footnotetext{
${ }^{2}[\ldots .$.$] signs may not be divorced from the concrete forms of social intercourse. ... and cannot exist, as$ such, without it.

${ }^{3}$ It does not offer ready-made answers. It offers ideas for formulating questions and ways of searching for answers.

${ }^{4}$ As discourses are social cognitions, socially specific ways of knowing social practices, they can be, and are, used as resources for representing social practices in text.

${ }^{5}$ Social practices are socially regulated ways of doing things [...].
} 
partimos da compreensão da 'brincadeira/brinquedo' como uma prática social constitutiva da infância e indissociável da realidade sociocultural em que está inserida e, portanto, 'reguladas' em diferentes graus e em diferentes maneiras. Presente nos ambientes particulares como as casas, ou nos espaços públicos como as escolas, creches e parques, o ato de brincar é uma atividade inerente à criança e essencial ao seu desenvolvimento sócio-interacional. Nesse sentido, Kishimoto (1997, p. 36) afirma que se considerarmos que as crianças "[...] aprendem em processos interativos, envolvendo o ser humano inteiro com suas cognições, afetividade, corpo e interações sociais”, o brinquedo desempenha um papel de grande relevância para o seu desenvolvimento. Corroborando com esta visão, Brougère (2001, p. 165) ressalta que "O jogo da criança não é apenas divertimento ou descontração; é também uma forma de ser e de aprender o mundo".

A atividade de brincar é onde ocorrem as expressões mais genuínas da cultura infantil. Como atividade social, é em sua associação com a cultura infantil que o ato de brincar assume seu papel mais poderoso. De fato, a socióloga Hannah Arendt (1971, p.231) descreve a atividade lúdica como "a maneira mais vívida e apropriada de se comportar no mundo, uma vez que constitui a única atividade que emerge espontaneamente da existência da criança”. Embora o 'instinto’ de brincar seja universal, acredita-se que a atividade de brincar seja culturalmente orientada, já que seu significado simbólico têm conotações específicas de acordo com o contexto social específico em que são realizadas.

Em sua forma tradicional, a atividade de brincar não costumava depender de objetos como brinquedos a serem estruturados, uma vez que as crianças costumavam recorrer a algum repositório de sua memória cultural, transmitido socialmente, o que implicava o uso de coisas que podiam encontrar em seu lugar de brincadeira - como borboletas ou pedaços de pau - ou adaptar objetos descartados, como "aros de roda e trapos ou pedaços de pano velho, o que costumava estimular a interação das crianças, ao mesmo tempo que evocava um sentido natural de infância (ALMEIDA, 2006).

É por meio da brincadeira que as crianças interagem com outros sujeitos, com a natureza e as demais coisas à sua volta. Brincando elas aprendem sobre si mesmas e se apropriam das práticas sociais e culturais dos grupos aos quais pertencem. A infância é, 
portanto, um período em que o ser humano está sendo constituído social e culturalmente, e a brincadeira, enquanto prática social, assume um papel fundamental como forma de interação social, de apropriação, ressignificação e reelaboração da cultura pelas crianças (BORBA, 2007). Nessa perspectiva, Barbosa, Martins e Mello (2017, p. 16o) destacam:

Brincar é uma das principais expressões do comportamento infantil. Por meio dos jogos e das brincadeiras, a criança interage com o seu meio físico e social, constrói conhecimentos, internaliza e produz cultura e também cria e afirma o seu modo peculiar de ser e estar no mundo.

As brincadeiras/brinquedos são recursos semióticos (ferramentas) para criar significados. Ao referir-se ao termo 'recurso semiótico', o qual considera um termochave na SS, van Leeuwen (2005) destaca que ele teria surgido com Halliday (1978, p.192), o qual afirma "que a gramática de uma língua não é um código, não um conjunto de regras para produzir sentenças corretas, mas um 'recurso para criar significados'” (apud VAN LEEUWEN, 2005, p. 3, tradução nossa ${ }^{6}$ ).

No livro Introducing Social Semiotics (2005) o autor estende essa ideia à 'gramática' de outros modos semióticos, e define 'recursos semióticos' como:

as ações e artefatos que usamos para comunicar, sejam eles produzidos fisiologicamente - com nosso aparelho vocal; com os músculos que usamos para criar expressões faciais e gestos etc. - ou por meio de tecnologias - com caneta, tinta e papel; com hardware e software de computador; com tecidos, tesouras e máquinas de costura, etc. (VAN LEEUWEN, 2005, p. 3, tradução nossa7).

O autor cita como exemplo uma careta que seria um sinal de desaprovação, e a cor vermelha um sinal de perigo. Reportando-se à dicotomia do signo linguístico definida por Ferdinand de Saussure, em que o signo é a união de um significante

\footnotetext{
${ }^{6}[. .$.$] that the grammar of a language is not a code, not a set of rules for producing correct sentences, but$ a 'resource for making meanings.

7 [...] as the actions and artefacts we use to communicate, whether they are produced physiologically with our vocal apparatus; with the muscles we use to create facial expressions and gestures, etc. - or by means of technologies - with pen, ink and paper; with computer hardware and software; with fabrics, scissors and sewing machines, etc.
} 
(imagem acústica) e um significado (conceito), um tipo de expressão facial ou uma cor, como formas observáveis, corresponderiam ao significante, e a ideia de desaprovação ou perigo, o significado (VAN LEEUWEN, 2005).

Os recursos semióticos não se restringem à fala, à escrita e à criação de imagens, eles estão presentes em quase toda a atividade humana, transmitindo algum significado através de várias semioses. Incluem modos óbvios de comunicação, como linguagem, gestos, imagens e música, mas também menos óbvios, como comida, roupas e objetos do cotidiano, todos com valor cultural e significado (VAN LEEUWEN, 2005).

Van Leeuwen (2005) destaca ainda que para a SS o que um signo representa é de alguma forma pré-determinado e também é afetado pelo seu uso. O potencial semiótico dos usuários é constituído por usos de recursos passados, presentes e todos os usos potenciais dos recursos a serem descobertos futuramente segundo suas necessidades e interesses específicos.

Apesar de serem motivados, os recursos não tem significados objetivamente fixos, e os usuários possuem liberdade para criar novas formas de utilização de recursos semióticos existentes. Desse modo, para a SS a compreensão de que os significados são plurais é crucial, pois assim como os dicionários não podem prever o significado que uma palavra terá em um contexto específico, outros tipos de inventários semióticos também não podem prever o significado de uma determinada expressão facial - por exemplo, uma careta, pois dependerá de um contexto específico (VAN LEEUWEN, 2005).

Contudo, isso não quer dizer que os significados estão absolutamente livres para todos, pois

Na vida social, as pessoas constantemente tentam consertar e controlar o uso de recursos semióticos - e justificar as regras que eles compõem - embora mais em alguns domínios do que em outros (VAN LEEUWEN, 2005, p. 5, tradução $\left.\operatorname{nossa}^{8}\right)$.

\footnotetext{
${ }^{8}$ In social life people constantly try to fix and control the use of semiotic resources - and to justify the rules they make up - although more so in some domains than in others.
} 
O significado dos sinais de trânsito, por exemplo, é fixado por regras precisas, por um 'código'. Essa mesma ideia se aplica aos recursos semióticos relacionados aos espaços. Discutimos, a seguir, as representações do espaço no discurso e os recursos semióticos de enquadramento usados para segregação nos espaços.

Van Leeuwen (2008, p.90, tradução nossa9), ao introduzir a discussão do tema 'espaço em discurso' aponta

[...] que discursos sobre o espaço fornecem entendimentos normativos do espaço e de seu uso no controle de práticas sociais. Para poder estudar isso, precisamos entender a 'Gramática do espaço', os recursos que temos para representar o espaço no discurso.

Ao descrever como os espaços em que as práticas sociais são executadas podem ser e são representados no discurso e também em imagens visuais, van Leeuwen (2008, p. 88, tradução nossa ${ }^{10}$ ) parte do seguinte ponto de vista: “[...] nossos entendimentos sobre o espaço derivam e podem estar diretamente ligados à ação, à maneira como usamos o espaço na atuação de práticas sociais”. O autor ainda ressalta que o aspecto histórico é importante na construção dos espaços, pois os mesmos recursos de enquadramento ou similares foram e são usados em diferentes contextos sociais e em diferentes períodos.

Portanto, os espaços são construtos sociossemióticos, um produto histórico, social e cultural que constrói sentidos em um determinado contexto social. As pessoas usam, adaptam e transformam recursos semióticos de enquadramento de acordo com os interesses e necessidades da época e do ambiente.

Van Leeuwen (2008) argumenta que nossos entendimentos sobre o espaço são sempre construídos em relação e com base nos enquadramentos espaciais das práticas sociais, portanto também na maneira como os corpos são posicionados no espaço.

Focando tanto em posições espaciais quanto em transições espaciais, van Leeuwen (2008) apresenta recursos discursivos para descrever e interpretar arranjos

\footnotetext{
9 [...] that discourses about space provide normative understandings of space and of its use in controlling social practices. To be able to study this, we need to understand the "grammar of space," the resources we have for representing space in discourse.

${ }^{10}[. .$.$] that our understandings of space derive from and can be linked directly to social action, to the way$ in which we use space in acting out social practices.
} 
espaciais, ou seja, recursos semióticos da comunicação visual para representar espaço, citando como exemplo uma pesquisa realizada em escolas secundárias de Londres, na qual junto com outros pesquisadores descreveu, entre outras coisas, arranjos feitos pelos professores nos espaço da sala de aula para estabelecer relações particulares com seus alunos e controlar o que deve e o que não deve acontecer nas aulas.

Entre as categorias analíticas dos recursos semióticos em espaços está o conceito de 'enquadramento', “[...] um princípio semiótico comum, realizado por diferentes recursos semióticos em diferentes modos semióticos" (VAN LEEUWEN, 2005, p. 14, tradução nossa $\left.{ }^{11}\right)$. No livro Reading Images (1996/2006), Kress e van Leeuwen introduziram a noção de 'enquadramento' no contexto da comunicação como as maneiras pelas quais elementos de uma composição podem ser visualmente conectados ou desconectados entre si, através da presença ou ausência de dispositivos de desconexão. Vetores como a semelhança de cores, por exemplo, podem conectar elementos de uma composição visual. Já a descontinuidade de cores estabelece uma desconexão.

O 'enquadramento’ está presente em diferentes contextos sociossemióticos. Utilizaremos como modelo de análise neste trabalho o inventário de tipos de enquadramento que van Leeuwen (2005) observou em um novo domínio, o enquadramento do espaço interior em escritórios e edifícios escolares. Ele constatou que os princípios semióticos multimodais realizam o mesmo trabalho semiótico tanto em representações verbais e visuais como em termos de realização física de pessoas e suas atividades: conectar ou desconectar, segregar ou separar, criar semelhança ou contraste.

A pesquisa realizada pelo autor mostrou que os limites entre espaços segregados podem ser de espessura diferente: paredes, portas de correr, telas ou até divisórias mais finas: "Partições, que variam de cortinas e telas frágeis a paredes sólidas, podem segregar espaços, e, portanto, as pessoas, grupos e / ou atividades realizadas neles" (VAN LEEUWEN, 2005, p 15, tradução nossa ${ }^{12}$ ). A seguir, apresentamos a análise.

\footnotetext{
${ }^{11}$ [...] framing is a common semiotic principle, realized by different semiotic resources in different semiotic modes.

${ }^{12}$ Partitions, ranging from curtains and flimsy screens to solid walls, can segregate spaces, and hence the people, groups and/or activities in them.
} 


\section{Análise semiótica do espaço}

A partir do conceito de 'espaço em discurso', introduzido por van Leeuwen, (2008), analisamos no texto, especificamente, os recursos semióticos de enquadramento que é um subsistema da metafunção composicional ${ }^{13}$, uma das estruturas de representação propostas por Kress e van Leeuwen (2006) na Gramática do Design Visual, cujo papel é estruturar/formatar os textos. No enquadramento é possível investigar a disposição dos elementos na imagem, o modo como estes (não) se integram na composição do espaço.

Nossa abordagem aqui aplica e adapta o esquema analítico proposto por van Leeuwen (2005) na pesquisa em que observou tipos de enquadramento em espaços físicos de escritórios e edifícios escolares, na qual constatou que os princípios semióticos multimodais realizam o mesmo trabalho semiótico tanto em representações verbais e visuais como em termos de realização física de pessoas e suas atividades: conectar ou desconectar, segregar ou separar, criar semelhança ou contraste.

O espaço analisado foi retratado na imagem fotográfica que foi publicada em 13/o5/2020, no jornal online The Mirror (MIRROR, 2020), em matéria sobre o retorno das aulas em uma escola da França após período de bloqueio por conta da pandemia da Covid-19.

A fotografia, que traz como legenda "As crianças nos quadrados de giz designados" ${ }^{14}$, retrata um grupo de crianças francesas que regressaram à escola, mas que precisam brincar à distância, em zonas delimitadas por marcas de giz no chão. A manchete da notícia destaca: "Crianças brincando em quadrados de giz mostram a realidade comovente de reabrir escolas" ${ }^{15}$. No subtítulo aparece o seguinte texto: "Uma

\footnotetext{
${ }^{13}$ Kress e van Leeuwen (2006) apresentam três sistemas inter-relacionados da metafunção composicional, a saber: Valor da informação, Saliência e Enquadramento.

14 The children in their assigned chalk squares.

${ }^{15}$ Kids 'playing' in chalk squares shows heart breaking reality of reopening schools.
} 
foto de crianças, com apenas três e quatro anos, em uma escola em Tourcoing, no norte da França, causou choque e indignação em todo o país" ${ }^{16}$.

Como nossa pesquisa tem como objetivo refletir sobre a ressignificação espaçointeracional em tempos de pandemia, procuramos analisar aqui os significados dos recursos semióticos de enquadramento na composição desse espaço representados na estruturação da imagem. Vejamos a fotografia:

Figura 1: Crianças brincando em quadrados de giz

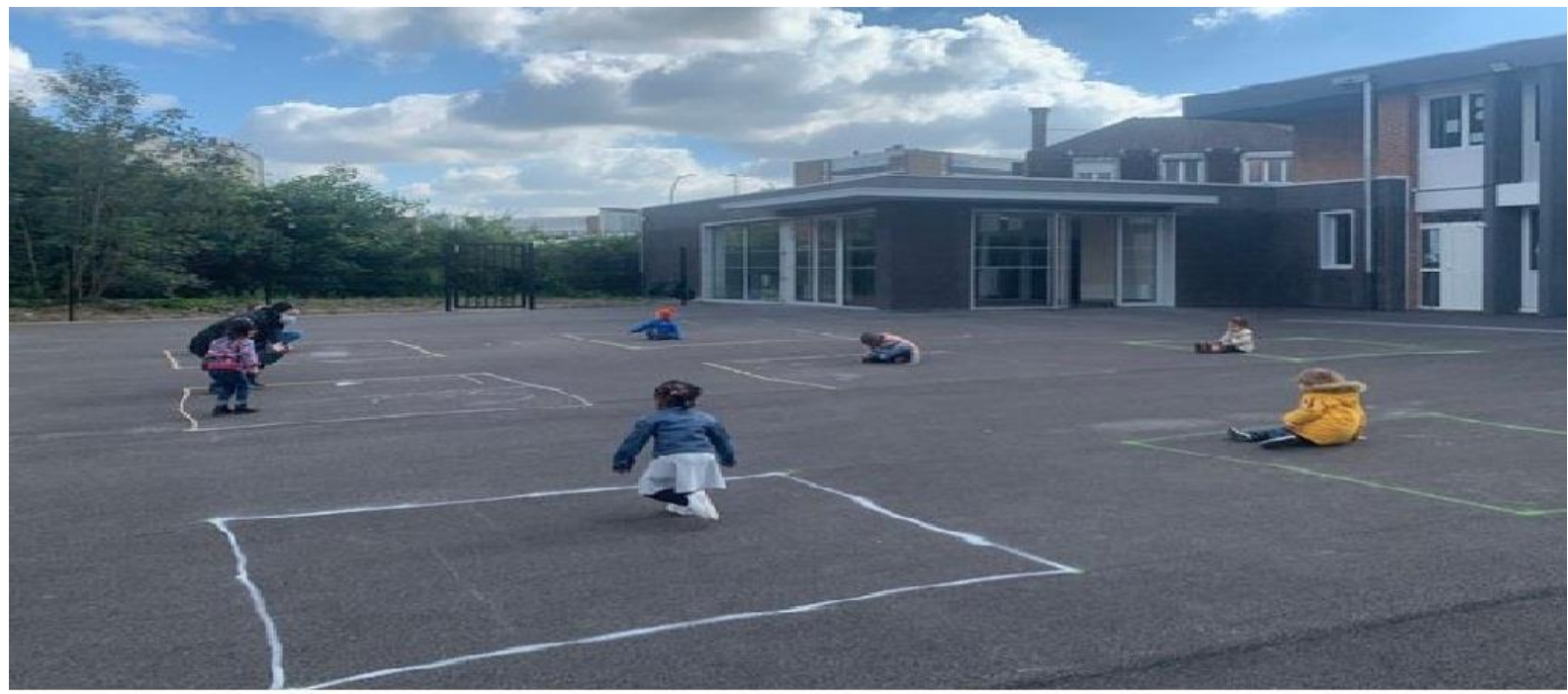

Fonte: Jornal online The Mirror (13/05/2020)

É possível observar por meio do texto verbal (manchete, legenda) e do texto não verbal (imagem fotográfica) que a matéria trata das mudanças que têm ocorrido no campo das relações sociais por causa da pandemia global da Covid-19, incluindo a ressignificação das formas de ocupação e convivência nos espaços públicos, bem como as formas de interagir e brincar que afetam diretamente as crianças.

A imprensa noticiou que escolas da China e do Japão, que retomaram as aulas após a quarentena, também adotaram novos arranjos espaciais ao nível do posicionamento do distanciamento corporal, como 'chapéu com régua', 'chapéu helicóptero' e asas para manter distância, entre outras medidas.

\footnotetext{
${ }^{16}$ A photo of children, aged just three and four, at a school in Tourcoing in northern France has caused shock and outrage across the country.
} 
Como já discorremos na fundamentação teórica, o enquadramento é um recurso importante do significado composicional que inclui as maneiras pelas quais os elementos de uma composição podem ser visualmente conectados (grau de continuidade) ou desconectados (grau de separação) entre si (VAN LEEUWEN, 2005).

O enquadramento pode ser realizado por diferentes recursos semióticos que se estende para além de uma composição verbo/visual, como o layout de jornal ou revista, por exemplo, podendo haver também em espaços físicos privados ou compartilhados pelas pessoas, como residências, salas de aula, restaurantes, escritórios, assentos em um trem ou restaurante etc. Os limites entre espaços segregados podem ser de espessuras diferentes. Exemplos de recursos de enquadramento em espaços estão no uso de barreiras físicas, como paredes, janelas, portas de correr, cercas, mesas ou até divisórias de ambientes mais finas como cortinas, telas; e até mesmo o espaço vazio ou a utilização de características de concepção como a cor da tinta para indicar a continuidade ou contraste (VAN LEEUWEN, 2005).

Com base na classificação das categorias (tipos) de enquadramento, apresentadas por van Leeuwen (2005), observamos na figura 1 que as zonas delimitadas por marcas de giz no chão no pátio da escola são recursos semióticos de desconexão usados tanto para 'segregação' como também para 'separação'. Na 'segregação', divisórias de materiais de vários tipos são usadas para segregar espaços, e, portanto, as pessoas, grupos e atividades que são desenvolvidas neles. Na 'separação', dois ou mais elementos são separados por espaço vazio, e isso pode ocorrer tanto nas partes de um texto em uma página, como também entre pessoas em um espaço (VAN LEEUWEN, 2005).

A Figura 1 mostra ao menos seis crianças juntamente com uma professora no pátio da escola brincando à distância, em zonas delimitadas por marcas de giz no chão. Apesar de estarem no mesmo espaço geral, os elementos que compõem o espaço, no caso as crianças e a professora, ocupam territórios diferentes, específicos, delimitados por quadrados pintados no chão, que funcionam como uma espécie de 'divisória', e isso faz com que eles sejam vistos num primeiro momento como pertencentes a ordens diferentes; não como um grupo, uma equipe, mas individualmente. Os quadrados foram projetados no chão como 'cercas' para manterem as crianças longe umas das outras, o que caracteriza o espaço como um tipo de enquadramento por ‘segregação'. 
Nesse sentido, outra dimensão que se pode adicionar ao esquema de segregação é o grau de controle ou liberdade permitido aos usuários dentro de um espaço. De acordo com o jornalista que tirou a foto, Lionel Top, as crianças foram instruídas a permanecerem em suas zonas para garantir o respeito ao distanciamento social.

Quanto à 'separação', do ponto de vista da SS esse tipo de enquadramento promove algum nível de interação dos elementos segregados que estão em locais onde linhas de visão permitem a comunicação. Pode ser possível alguma interação mínima entre os espaços. Como visto na figura 1, apesar dos quadrados no chão e do espaço vazio entre eles, que limitam a interação, há o compartilhamento de um espaço aberto que ajuda a promover a comunicação, bem como uma necessidade frequente da criança entrar em contato com as demais crianças e a professora para ver o que os outros estão fazendo e repetir as atividades, dando o sentido de equipe.

Portanto, constatamos que a nova configuração do enquadramento do espaço pátio da escola se dá por meio da ‘segregação’ (cada criança confinada em seu quadrado) e ‘separação’ (crianças são separadas uma das outras pelo espaço vazio entre os espaços). Discorremos, a seguir, acerca do potencial simbólico das formas geométricas.

Linhas retas, círculos, curvas e todas as formas geométricas implicam significados diferentes. Kress e van Leeuwen (2006) destacam que os significados abstratos das formas geométricas básicas como o quadrado e o círculo descritos em dicionários de símbolos visuais são motivados de duas maneiras. Primeiro, eles derivam das propriedades das formas ou dos valores dados a essas propriedades em contextos sociais e culturais específicos. Segundo, esses significados derivam das qualidades comuns que são detectadas em tais objetos em nosso ambiente como circulares ou retangulares quando abstraída a forma básica subjacente e a partir dos valores associados a essas qualidades em diferentes contextos. Os autores chamam a atenção para as oposições fundamentais entre quadrado e círculo.

Círculos e formas curvas geralmente são os elementos que associamos a uma ordem orgânica e natural, ao mundo da natureza orgânica - e os significados místicos que podem estar associados a eles derivam disso. Angularidade que associamos ao mundo inorgânico, cristalino ou ao mundo da tecnologia, que é um mundo que criamos a nós mesmos e, portanto, um mundo que podemos / pelo menos em princípio, compreenda plena e racionalmente. $\mathrm{O}$ mundo da 
natureza orgânica não é da nossa fazendo, e sempre manterá um elemento de mistério (KRESS e VAN LEEUWEN, 2006, p. 55, tradução nossa ${ }^{17}$ ).

Diferentemente do círculo (formas curvas), que são representações de uma ordem orgânica natural da sociedade, como por exemplo, o sol, a lua, a barriga da mulher grávida, quadrados e retângulos são vistos como elementos da ordem mecânica e tecnológica do universo da construção humana que dominam a forma de nossas cidades, nossos prédios, nossas estradas, bem como a forma de muitos objetos que usamos na vida cotidiana, incluindo os porta-retratos, que hoje em dia raramente têm uma moldura redonda. Ainda de acordo com kress e van Leeuwen, 2006, p. 56, tradução nossa ${ }^{18}$ ), essas qualidades comuns que são verificáveis "nesses grupos de objetos (digamos, 'ciclos da natureza' e 'poder masculino') serão evidentemente lidos e avaliados diferentemente em diferentes contextos sociais".

Formas geométricas podem transmitir significados visualmente que não são necessariamente também transmitidos verbalmente. De acordo com alguns dicionários, o “quadrado representa 'honestidade, retidão e significado operário'; [...] 'representa o mundo e denota ordem'” (KRESS e VAN LEEUWEN, 2006, p. 54, tradução nossa19). Já os círculos são interpretados como "denotando infinitude, calor, proteção [...] ou como o símbolo tradicional da eternidade e dos céus" (KRESS e VAN LEEUWEN, 2006, p. 54, tradução nossa $\left.{ }^{20}\right)$.

Formas angulares também podem ser vistas como agressivas, opressivas, que retiram do indivíduo a autonomia, a escolha e a liberdade. Também tem sido sugerido

\footnotetext{
${ }^{17}$ Circles and curved forms generally are the elements we associate with an organic and natural order, with the world of organic nature - and such mystical meanings as may be associated with them derive from this. Angularity we associate with the inorganic, crystalline world, or with the world of technology, which is a world we have made ourselves, and therefore a world we can/ at least in principle, understand fully and rationally. The world of organic nature is not of our making, and will always retain an element of mystery.

${ }^{18}[. .$.$] in these groups of objects (say, 'nature's cycles' and 'male power') will evidently be read and valued$ differently in different social contexts [...].

${ }^{19}$ the square represents' honesty, straightness and workmanlike meaning'; [...], it 'represents the world and denotes order'.

${ }^{20}$ Denoting 'endlessness, warmth, protection' [...], or as 'the traditional symbol of eternity and the heavens'.
} 
que quadrado é um símbolo de poder. Já as formas circulares oferecem uma forte sugestão de movimento; podem significar comunidade, cooperação e unidade (KRESS e VAN LEEUWEN, 2006).

Talvez isso traga ao leitor da figura 1 um viés inconsciente motivado da divisória utilizada na forma de quadrados como uma 'estrutura social' considerada opressora. É possível observar essa interpretação na manchete: “Crianças brincando em quadrados de giz mostram a realidade comovente de reabrir escolas"; e no corpo da notícia: "Uma fotografia comovente de crianças de escolas maternais sentadas sozinhas em suas próprias 'seções de isolamento' causou choque e indignação na França [...] mostra um grupo de meninos e meninas sendo mantidos afastados um do outro usando quadrados marcados com giz" (grifos nossos).

Portanto, concluímos que as representações de afastamento/distância social, os quadrados desenhados no chão (segregação) e os espaços vazios (separação) entre as crianças são usados como um mecanismo de definição de limites, e esses sentidos são reforçados pelos princípios desses significados da forma geométrica 'quadrado'. Nesse caso a relação é, obviamente, simbólica, imaginária.

\section{Considerações finais}

Neste trabalho, cujo objetivo foi refletir sobre a ressignificação espaço/interacional em tempos de pandemia no contexto educacional, procuramos analisar, com base na abordagem da Semiótica Social (VAN LEEUWEN, 2005, 2008; KRESS e VAN LEEUWEN, 2006), os recursos semióticos de enquadramento na composição do espaço. Partindo do pressuposto de que os tipos de enquadramento indicam um potencial de significado, não um significado específico, e seu uso será diferente em diferentes contextos (VAN LEEUWEN, 2005), buscamos compreender a articulação dos diversos modos semióticos utilizados nas práticas de enquadramento do espaço em práticas sociais no contexto da pandemia. Buscamos mais especificamente, responder a seguinte pergunta: o que o enquadramento dos espaços na pandemia significa no caso das escolas? 
A pandemia global da Covid-19 impôs à sociedade novas formas de convivência entre as pessoas para evitar o contágio. A principal delas é o distanciamento social, novos arranjos espaciais ao nível de distanciamento social-físico.

Aplicamos neste trabalho o esquema analítico proposto por van Leeuwen (2005) para observar tipos de enquadramento no espaço que foi retratado em uma imagem fotográfica, o pátio de uma escola (creche), publicada em um jornal, cuja matéria tratava do retorno das aulas em uma escola da França após período de bloqueio por conta da pandemia.

A análise constatou que em tempos de pandemia novas estratégias semióticas estão surgindo para criar fronteiras entre as pessoas, novas representações de afastamento/distância social. Em outras palavras, um novo padrão de enquadramento foi introduzido em várias configurações dos espaços públicos, entre eles, as instituições de ensino.

Os espaços que existem nas escolas (creches) naturalmente enfatizam a interação social (contato físico) das crianças. As atividades recreativas são alguns dos elementos básicos da educação infantil, normalmente realizadas em espaços abertos, como o pátio da escola, uma quadra, um playground, ou uma sala. No espaço retratado na fotografia, algumas crianças brincam juntamente com uma professora em um pátio de uma escola. Então por que a imagem causou indignação e provocou um intenso debate sobre o retorno das escolas após a quarentena? A resposta pode estar na ressignificação dos espaços por meio do enquadramento.

No espaço analisado por meio da imagem, observamos primeiramente que ele tem um enquadramento por 'segregação', pois os elementos estão completamente desconectados. Essa desconexão entre as partes reforça o sentido de individualidade. $\mathrm{O}$ que mais chama a atenção na imagem e que causa uma reação negativa são as crianças cercadas por um quadrado pintado no chão ao redor delas, o que caracteriza distância social.

Observamos que há também o enquadramento por 'separação' através do espaço vazio que há entre um quadrado e outro ocupados pelas crianças, o que permite certo grau de interação social através da visualização e da audição. 
Esses detalhes de enquadramento criam uma importância em relação aos outros elementos da unidade semiótica, atraindo a atenção do olhar do leitor. Na foto analisada, a construção do espaço contempla o exterior da escola que mostra o pátio composto por espaço amplo, em que figuram poucos elementos além das crianças, como a vista do prédio ao fundo, algumas árvores etc.

O que se destaca nesse âmbito são os sentidos que cada elemento constitutivo do espaço pode indicar. No caso do espaço em análise representado na foto, é importante observar que os elementos de enquadramento ‘segregação’ e ‘separação’ se integram para a construção do sentido. São sistemas inter-relacionados dos elementos de uma composição, que reforçam a ideia de distanciamento, abandono, vazio.

Nessa ressignificação dos espaços, merecem destaques os quadrados pintados no chão que além de funcionarem como uma barreira física, também limitam os movimentos das crianças e imprimem uma orientação para a não ultrapassagem daquele limite. No caso da figura geométrica quadrado, sua representação sócio-históricocultural remete aos elementos da ordem mecânica comum as formas angulares que oferecem uma forte sugestão de agressividade, opressão e poder. No exemplo, o foco da imagem bem definido pela divisão do espaço, no qual as crianças estão enquadradas pelas linhas divisórias representadas pelas marcas de giz no chão, a segregação do espaço pode ser 'lida' como algo que significa estar constantemente vigiado, supervisionado, controlado.

Este exemplo mostra que em relação à ressignificação espaço/interacional em tempos de pandemia, o dispositivo de enquadramento do espaço foi projetado para atender as recomendações de distanciamento social, corroborando com o que afirma van Leeuwen (2005, p. 26, tradução nossa ${ }^{21}$ ): “À medida que a sociedade muda, novos recursos semióticos e novas maneiras de usar recursos semióticos podem ser necessários”. Os novos recursos semióticos de enquadramento do espaço físico analisado foram zonas delimitadas por marcas de giz no chão e o espaço vazio entre cada zona.

\footnotetext{
${ }^{21}$ As society changes, new semiotic resources and new ways of using existing semiotic resources may be needed.
} 
Este exemplo, portanto, gera uma nova variável, algo que não encontrávamos até então, ao considerar os tipos de enquadramento nas escolas, mostrando que os limites entre espaços segregados podem ser cada vez mais diferentes.

Nessa direção, é possível postular que: a) as caracterizações (construções) dos espaços por meio do enquadramento são elementos produtores de sentido que podem ser lidos como textos; b) a escolha entre diferentes estruturas composicionais de enquadramento bem como diferentes usos de figuras geométricas afetará o significado; c) as estruturas espaciais apontam para diferentes formas de interação social; d) os recursos semióticos de enquadramento em qualquer tipo de representação são histórico, social e culturalmente motivados; e) os recursos semióticos de enquadramento dos espaços são utilizados com base nos interesses e necessidades de um período histórico.

Diante disso, é preciso buscar 'ler' o que esses recursos semióticos de enquadramento dos espaços em tempos de pandemia significam nas práticas sociais no contexto educacional.

\section{Referências}

ALMEIDA, D. Icons of Contemporary Childhood: A Visual and Lexicogrammatical Investigation of Toy Advertisements. 215 f. Tese de Doutorado. Florianópolis: Universidade Federal de Santa Catarina, 2006.

ARENDT, H. A Crise na Educação. In: Entre o Passado e o Futuro. São Paulo: Editora Perspectiva, 1971, p. 221-247.

BARBOSA, R. F. M.; MARTINS, R. L. D. R.; MELLO, A. S. Brincadeiras lúdico-agressivas: tensões e dificuldades no cotidiano da Educação Infantil. Movimento, Porto Alegre, v. 23, n. 1, p. 159-170, jan./mar. de 2017.

BORBA, A. M. A brincadeira como experiência de cultura na educação infantil. Revista Criança do Professor de Educação Infantil, n. 44, p. 12-14, nov. 2007.

BROUGÈRE, G. Jogo e Educação. Trad. Patrícia Chittoni Ramos. Porto Alegre: Artes Médica, 2001. 
FIGURA 1. Reprodução de imagem de Lionel Top. Disponível em: < https://i2prod.mirror.co.uk/incoming/article22018441.ece/ALTERNATES/s615b/o_He artbreaking-pictures-show-what-schools-could-look-like-as-kids-forced-to-stay-apartin-playground.jpg >. Acesso em: 30 de maio 2020.

KISHIMOTO, T. M. O jogo e a educação infantil. In: Jogo, Brinquedo, Brincadeira e Educação. KISHIMOTO, T. M. (Org). 2. ed. São Paulo: Cortez, 1997.

KRESS, G.; VAN LEEUWEN, T. Reading images: The grammar of visual design. 2nd ed. London: Routledge, 2006.

MIRROR, The. Kids 'playing' in chalk squares shows heart breaking reality of reopening schools. Londres, 13 de maio de 2020. Disponível em: <https://www.mirror.co.uk/news/world-news/kids-playing-chalk-squares-shows22018391>. Acesso em: 30 de maio 2020.

VAN LEEUWEN, T. Introducing Social Semiotics. London, New York: Routledge, 2005. Discourse and practice: new tools for critical discourse analysis. New York: Oxford University Press, 2008.

Recebido em 28/07/2020. Aprovado em 18/11/2020. 